\title{
The History of Dusun Kimaragang Tribe
}

\section{Masliah Maun $^{1 *}$ and Uqbah Iqbal ${ }^{2}$}

${ }^{1}$ Independent Author

${ }^{2}$ School of History, Politics and Strategy, Faculty of Social Sciences and Humanities, UKM 43650, BangiSelangor, Malaysia

\section{Opinion}

Kimaragang tribe is one of the Dusun tribe in Sabah, among the oldest, which means the original inhabitants who inhabit a place after a number of other tribes such as the Rungus, Tambanuo, Rivers and others. Kimaragang is a group of the Kadazan due share the same customs and numerous in the north of Sabah, namely Kota Marudu, Pitas, Teluk Marudu and Malobang. Kimaragang tribe uses Dusun language in conversations between them and carries out agricultural, animal husbandry and fishery activities, in livelihood, but nowadays there are also already working as civil servants and private sector and has his own business. Formerly, the tribe's only animist beliefs but nowadays, most of these tribes are Christians and there is also a small number professing the religion of Islam.

Kimaragang name trusted based on the color of clothing worn by Kimaragang tribe, where their costumes look red in the distance. Clothing is derived from tree bark of a tree called Paliu and Timbagan. The trick is to take the bark and beaten repeatedly using wooden sticks until soft and smooth. Then make the bark that is soft and smooth as clothes that cover the body from the chest to the knees for women and as santut (clothing like pants that cover a certain part of the male) for adult males.

There is also the story at first there were Tongod people who held puawang hereditary (friendly) held gatherings and invite Kimaragang people as their guests. Kimaragang people came en masse and visible from afar looks reddish because they wearing a red dress uniform on Tongod people observations. Because they feel obsessed and wonder, Tongod people has called their invited guests as Kimaragang which means reddish and the title remained up to now.

Kinaling cloth is Dusun Kimaragang traditional ethnic costume. Usually Dusun Kimaragang traditional ethnic costume is black with colorful sashes made of silver and rattan. Traditional clothing is usually worn at the time of draw and Dusun Kimaragang traditional dance, namely Kilintangan dance. Clothing is also graced with a cap made of rattan or bamboo woven together with a long pink fabric to complement their traditional dress to make it more attractive and unique.

Their food traditions known as 'bosou or tonsom', linopot and sinalau. Bosou is a type of food such as orange or sambal that is usually made of raw meat or fish river hunted. Its preparation is like meat or raw fish meat fermented with rice, salt and fruit as a preservative which is stored in a container and sealed for a week or until completely cooked before it can be eaten. While linopot is rice wrapped with leaves from either tree leaf stage or Doringin tree leaves tree. Linopot contains rice that has been mixed with other traditional foods such as guol or yams, tawadak or pumpkin and cassava. Rice wrapped in leaves will produce a fragrance and natural fragrance still used up to now during the festive season and there are crowds in villages like weddings for example. Sinalau is a meat that is smoked over a fire of the dried meat, often these communities have used this method to extend shelf-life of food either boars or whatever kind of meat that is not perishable and can be eaten in a long time. But basically, this tribe food is boiled food only.

The tribe dance called mongigol for men and magandak for women. The name of the music is pinakang that using traditional tools such as tagung and a xylophone. There is also singing in a tribe called tabai insi and tidindot and also had some classic literary name of boor, rina'at and sunda'at. Art music and dance from Kimaragang is different from other tribes because it is softer, melodic and harmonic. Harvest Festival is celebrated by this tribe in every month of May each year, which falls on 30 and 31 May. Many of the activities carried out during the celebration of the match took place apart from the singing competition and highlights the beauty pageant or unduk ngadau, traditional dances and ceremonies conducted by bobohizan (chief priest). At this time, all the tribes will wear their traditional costumes and have fun other than dancing sumazau with the tradition tools and serving specialty drinks, namely rice wine or rice wine.
*Corresponding author: Masliah M, Independent Author, BangiSelangor, Malaysia, Tel: +60389215555; E-mail: Ungulyea@gmail.com

Received July 20, 2016; Accepted July 25, 2016; Published August 02, 2016

Citation: Maun M, Iqbal U (2016) The History of Dusun Kimaragang Tribe. Intel Prop Rights. 4: 158. doi:10.4172/2375-4516.1000158

Copyright: ( $) 2016$ Maun M, et al. This is an open-access article distributed under the terms of the Creative Commons Attribution License, which permits unrestricted use, distribution, and reproduction in any medium, provided the original author and source are credited. 